\title{
Interspecific Hybridization of Fragaria vesca subspecies with $F$. nilgerrensis, $F$. nubicola, $F$. pentaphylla, and $F$. viridis
}

\author{
R.H. Bors ${ }^{1}$ and J.A. Sullivan ${ }^{2}$ \\ Department of Plant Agriculture, University of Guelph, Guelph, Ontario N1G 2W1, Canada
}

\begin{abstract}
ADDITIONAL INDEX WORDS. strawberry, diploid, synthetic octoploid, breeding
Abstract. The potential of using Fragaria vesca $\mathrm{L}$. as a bridge species for interspecific hybridization to $F$. nilgerrensis Schlect, $F$. nubicola Lindl., $F$. pentaphylla Losinsk, and $F$. viridis Duch. was investigated using a wide germplasm base of $40 \mathrm{~F}$. vesca accessions. This study was successful in producing many hybrids between $F$. vesca and other diploid species indicating its value as a bridge species. Of the species used as males, $F$. nubicola, $F$. pentaphylla, and $F$. viridis accessions were more successful, averaging 8 to 16 fruit and 16 to 25 seeds/fruit. It was most difficult to obtain hybrids with $\boldsymbol{F}$. nilgerrensis, which had only three seeds per fruit. Differences among pollen donors were minimal when hybrid seeds were germinated in vitro. For different species combinations, $75 \%$ to $99 \%$ of seeds had embryos and $77 \%$ to $89 \%$ of these embryos germinated. The lack of significant differences in crossability variables among the four $F$. vesca subspecies [i.e., ssp. americana (Porter) Staudt, ssp. bracteata (Heller) Staudt, ssp. vesca L., and ssp. vesca var. semperflorens L.] demonstrated the similarity between these species and the strong potential for gene flow between $F$. vesca and other diploid species. As European and North American $F$. vesca subspecies are not sufficiently divergent to differ in interspecific hybridization, $F$. vesca may be a younger species rather than an older progenitor species.
\end{abstract}

The synthetic octoploid (SO) system (Evans, 1977) was developed as a means to incorporate germplasm of $2 \mathrm{x}, 4 \mathrm{x}$, and $6 \mathrm{x}$ Fragaria species into octoploid hybrids. This system bypasses ploidy level differences and facilitates introgression of $2 x, 4 x$, and 6x species into the cultivated strawberry (Fragaria $\times$ ananassa Duch.) via the synthetic octoploid (Evans, 1977). The first step of a synthetic octoploid system is the intercrossing of diploid species to create diploid hybrids (Evans, 1977).

The use of a bridge species (or pivotal genome) to facilitate interspecific crosses has been valuable for introgressing diploid species into polyploid cereals (Gustafson and Dera, 1989; Gustafson and Sears, 1993) but no suggestions for bridge species have been mentioned in previous investigations of SO systems with Fragaria (Evans, 1977; Sebastampillia and Jones, 1976). Fragaria vesca is a logical choice as a bridge species for crosses with other diploid Fragaria species in the initial stage of the SO system because it has been successfully hybridized with several Fragaria species including octoploid cultivars (Ahmadi and Bringhurst, 1992; Evans, 1964, 1974, 1977; Evans and Jones, 1967; Fadeeva, 1966; Federova, 1946; Sebastiampillia and Jones, 1976; Senanayake and Bringhurst, 1967; Staudt, 1959, 1967, 1989; Trajkovski, 1993; Williams, 1959; Yarnell, 1931), may be progenitor of other Fragaria species (Bringhurst and Gill, 1970; Duchesne in Darrow, 1966; Longley in Darrow, 1966; Nurnberg-Kruger, 1958; Staudt, 1953) and may, therefore, be closely related to other diploid species. Fragaria vesca may be best utilized as a female parent to overcome incompatibility mechanisms in some diploid species (Evans and Jones, 1967). The chloroplast genome of $F$. vesca has greater genetic diversity compared to other Fragaria species (Harrison et al., 1993, 1997), which may be important to the success of interspecific hybridization (Stoskopf et al., 1993).

Received for publication 19 July 2003. Accepted for publication 17 Mar. 2005. ${ }^{1}$ Present address: Assistant Professor, Dept. of Plant Science, Univ. of Saskatchewan, Saskatoon, Saskatchewan, Canada.

2Corresponding author: asulliva@uoguelph.ca
In addition, $F$. vesca cytoplasm and genomes are more amenable than other Fragaria species to chromosome doubling by colchicine (Fadeeva, 1966; Sebastiampillai and Jones, 1976), another important consideration in the SO system.

If $F$. vesca is the progenitor to other diploid species (Duchesne in Darrow, 1966; Longley in Darrow, 1966; Nurnberg-Kruger;1958; Staudt,1953), then $F$. vesca subspecies may differ in relatedness and, hence, crossability with other diploid species. With a range of distribution over five continents, F. vesca subspecies could have become geographically isolated and diverged sufficiently to differ in interspecific crossability. At least one $F$. vesca population in Neb. was unique due to its isolation (Potter et al., 2000). Although it has been suggested that $F$. vesca is not highly variable genetically (Potter et al., 2000; Reed, 1966), there have been several studies that have highlighted morphological differences of plant form, fruit, leaves and flowers of $F$. vesca subspecies (Ahmadi and Bringhurst, 1990; Harrison et al., 1993, 1997). Fragaria vesca subspecies also differed in chloroplast DNA restriction fragment length polymorphism markers (Harrison et al.,1997), the number of genes governing photosensitivity (Ahmadi and Bringhurst, 1990) and sex expression (Ahmadi and Bringhurst, 1991). Several subspecies need to be included in any studies to determine if these differences impact on interspecific hybridization.

Fragaria vesca's adaptation to low light levels (Chabot and Chabot, 1977) and cool temperatures (Bauer, 1976) may be especially useful for breeding cultivars for northern temperate areas and enhanced late season growth (Bauer, 1976), flower bud initiation in the fall, and yield potential if these adaptations were successfully transferred into cultivars. Fragaria vesca fruit also has a very desirable aroma that could be used to improve fruit quality of modern cultivars (Ahmadi and Bringhurst, 1992). The use of $F$. vesca subspecies in interspecific crosses in this study may also aid in understanding divergence and evolution in Fragaria. Since $F$. vesca is distributed across five continents with broad adaptation to diverse conditions (Darrow, 1966) crossability differences among $F$. vesca subspecies could also be exploited to optimize an SO system. 
In this study, F. vesca ssp. americana, ssp. bracteata, ssp. vesca, and ssp. vesca var. semperflorens are examined for differences in crossability. The latter group, ssp. vesca var. semperflorens, is the cultivated form of $F$. vesca, which has diverged through artificial selection.

The objective of this study is to determine the crossability of four $F$. vesca subspecies with the accessions of four other diploid species. In addition, several accessions within a subspecies were used to investigate the potential divergence of species. This information could be important for optimizing a crossing strategy for the early stages of the SO system (Evans, 1977) and may provide insight into relationships between Fragaria species.

\section{Material and Methods}

GermPLASM AND CROSSING DESIGN. The $F$. vesca female parents used in this study (Table 1) were grouped by subspecies (ssp. americana, ssp. bracteata, ssp. vesca, or ssp. vesca var. semperflorens). One F. vesca accession was used as a pollen source for control crosses and six male parents [i.e., F. nilgerrensis (nil1), F. nubicola (nub1, nub2), F. pentaphylla (pen1), and F. viridis (vir1 and vir2) (Table 2)] were used for interspecific crosses. Ten $F$. vesca var. semperflorens cultivars were assigned to each of the three blocks but accessions of the three wild subspecies (i.e., ssp. americana, ssp. bracteata, ssp. vesca) were randomly distributed among the blocks.

Controlled crosses with $F$. vesca pollen were done to verify that emasculation and pollen storage techniques were correct and for comparison with interspecific crosses. VW69 was used for control crosses because it was native to Asia (unlike other $F$. vesca accessions in the study) and produced abundant pollen. The number of male/female combinations was maximized by crossing the genotypes within blocks. Each female genotype (Table 1) was pollinated with up to seven accessions for interspecific crosses. Data from control crosses are discussed in results but are not included in the data set of interspecific crosses. The recessive everbearing and nonrunnering traits of var. semperflorens cultivars were useful as morphological markers to easily identify true hybrids from selfs.

Crosses were done over a period of several months as different genotypes flowered. An attempt was made to pollinate each female with an equal number of the different species that were used as pollen donors. Choice of parents was made to maximize the number of accession combinations and, thus, sample the greatest amount of diversity.

Handling OF Parent Plants. In early November, dormant plants were dug from the field and stored bare root in a freezer at $-1{ }^{\circ} \mathrm{C}$. From late December to early March, plants were potted with a soilless mix (Promix BX; Premier Horticulture, Red Hill, Pa.) in either 3- or 6-L pots (Plant Products, Brampton, Ont.) and grown in the greenhouse at Guelph, Ont. Plants were watered as required with deionized water and fertilized with fertilizer solution [20N-3.5P-16.6K (Plant Products, Brampton, Ont.) at a concentration of $267 \mathrm{mg} \cdot \mathrm{L}^{-1}$ with a $\mathrm{pH}$ of 6.0 phosphoric acid]

Floral induction. Some $F$. nilgerrensis, $F$. nubicola, $F$. pentaphylla and $F$. viridis did not bloom under the greenhouse conditions described above. They required additional short day and temperature treatments $\left[4\right.$ weeks, 10 -h photoperiod, $18^{\circ} \mathrm{C}$ day $/ 15^{\circ} \mathrm{C}$ night temperature in a growth chamber (model EY8M; Controlled Environments, Winnipeg, Man.)] to induce flowering. The flower induction treatment was applied in late winter or early spring to greenhouse plants that showed no signs of blooming.
Table 1. Fragaria vesca accessions used as female parents for interspecific hybridization with four diploid Fragaria species. Accessions are grouped by subspecies.

\begin{tabular}{|c|c|c|}
\hline $\begin{array}{l}\text { Genotype and Guelph } \\
\text { identification code }\end{array}$ & $\begin{array}{c}\text { Species and accession number from } \\
\text { original source }\end{array}$ & Source of germplasm ${ }^{2}$ \\
\hline \multicolumn{3}{|c|}{ F. vesca ssp. vesca var. semperflorens (day-neutral cultivars) } \\
\hline vcv02 & PI 551517, Alpine & NCGR \\
\hline vcv04 & PI 551827, Yellow Wonder & NCGR \\
\hline vcv06 & CFRA1185.001, Golden Alpine & NCGR \\
\hline vcv07 & Pineapple Crush & Park Seed \\
\hline vcv10 & Alexandria & Thompson \& Morgan \\
\hline vcv11 & Ruegen & Richters Seeds \\
\hline vcv13 & Mignonette & Park Seed Co. \\
\hline vcv14 & Golden Sprite & Ornamental Edibles \\
\hline vcv20 & Alpine Strawberry & White Flower Farms \\
\hline vcv22 & FRA 2193 & IPK Genbank \\
\hline \multicolumn{3}{|c|}{ F. vesca spp. vesca (wild type from Europe) } \\
\hline vw 07 & PI 551792 & NCGR \\
\hline vw 09 & PI 551890 & NCGR \\
\hline vw10 & PI 551892 & NCGR \\
\hline vw11 & PI 551893 & NCGR \\
\hline vw12 & PI 551909 & NCGR \\
\hline vw13 & PI 552273 & NCGR \\
\hline vw14 & PI 552274 & NCGR \\
\hline vw16 & PI 552239 & NCGR \\
\hline vw22 & FRA 13197 & IPK Genbank \\
\hline vw38 & PI 552242 & NCGR \\
\hline \multicolumn{3}{|c|}{ F. vesca spp. bracteata (wild type from western North America) } \\
\hline vw 02 & PI 551519 & NCGR \\
\hline vw 06 & PI 511791 & NCGR \\
\hline vw23 & PI 551524 & NCGR \\
\hline vw24 & PI 551551 & NCGR \\
\hline vw25 & PI 551644 & NCGR \\
\hline vw26 & PI 551645 & NCGR \\
\hline vw57 & PI 148 & CCG \\
\hline vw58 & PI 418 & CCG \\
\hline \multicolumn{3}{|c|}{ F. vesca ssp. americana (wild type from eastern North America) } \\
\hline vw17 & PI 552246 & NCGR \\
\hline vw29 & PI 552241 & NCGR \\
\hline vw30 & PI 552247 & NCGR \\
\hline vw32 & PI 552286 & NCGR \\
\hline vw33 & Grand River, Cambridge, Ont. & Spencer Murch \\
\hline vw34 & Cambridge, Ont. & collected by author \\
\hline vw35 & PI 552243 & NCGR \\
\hline vw36 & PI 552244 & NCGR \\
\hline vw47 & PI 551898 & NCGR \\
\hline vw48 & PI 551908 & NCGR \\
\hline vw49 & Smithfield, Ont. & collected by author \\
\hline vw53 & Newcastle, Ont. & collected by author \\
\hline
\end{tabular}

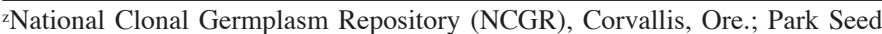
Co. Greenwood, S.C.; Thompson \& Morgan, Jackson, N.J.; Richters Herbs, Goodwood, Ont.; Ornamental Edibles, San Jose, Calif.; White Flower Farm, Litchfield, Conn.; Inst. fur Pflanzengenetik und Kulturpflanzenrofschung (IPK Genbank), Gatersleben, Germany; Canadian Clonal Genebank (CCG), Agriculture and Agri-Food Canada, Harrow, Ont. 
Table 2. Fragaria species accessions used as pollen donors in crosses with $F$. vesca.

\begin{tabular}{llcl}
\hline Species & $\begin{array}{c}\text { Accession no. } \\
\text { from source }\end{array}$ & $\begin{array}{c}\text { Accession code } \\
\text { for this study }\end{array}$ & Source $^{\text {S }}$ \\
\hline F. nilgerrensis & CFRA 1188.000 & nil 1 & NCGR \\
F. nubicola & PI 551851 & nub1 & NCGR \\
& PI 551853 & nub 2 & NCGR \\
F. pentaphylla & PI 881143 & pen 1 & RBG \\
F. viridis & PI 551741 & vir 1 & NCGR \\
& PI 551742 & vir 2 & NCGR
\end{tabular}

$\overline{{ }^{z} \text { National Clonal Germplasm Repository (NCGR), Corvallis, Ore.; Royal }}$ Botanical Garden (RBG), Edinburgh, Scotland.

Pollination Procedures. All flowers were emasculated prior to crossing. A method to store pollen to facilitate crossing was adapted from MacFarlane Smith et al. (1989). Pollen was stored with a desiccant at 3 to $4{ }^{\circ} \mathrm{C}$.

SEed COLlection AND STORAGE. Ripe fruit were either crushed on petri dishes or placed intact into airtight jars containing desiccant. Crushed fruit were air-dried at room temperature. Once dry, achenes were rubbed off, counted and stored at room temperature or in a refrigerator at 3 to $5{ }^{\circ} \mathrm{C}$. Only large plump seed were collected and stored. Intermediate and small-sized seeds were assumed to contain no embryos based on previous investigations (unpublished data).

IN VITRO GERMINATION. The in vitro germination technique of Miller et al. (1992) was modified for use in this research. This technique was originally developed for use with $F$. xananassa seed, but was adapted for seeds resulting from interspecific hybridizations. Murshige and Skoog medium (Sigma-Aldrich Canada, Oakville, Ont.) was prepared with no hormones as described by Miller et al. (1992) but Gellan gum agar (Scheweizerhall, South Plainfield, N.J.) at $2.5 \mathrm{~g} \cdot \mathrm{L}^{-1}$ was substituted for agar. Acid washed, activated charcoal (Gibco Laboratories/Life Technologies, Grand Island, N.Y.) was added at $3.0 \mathrm{~g} \cdot \mathrm{L}^{-1}$ to darken the medium. In a previous study (data not reported), shoots of seedlings germinated on clear medium often grew inverted or laterally. Medium (7.5 $\mathrm{mL}$ ) was placed in 30-mL glass French squares, autoclaved (model 3021; AMSCO, Erie, Pa.) at $121^{\circ} \mathrm{C}$ for $20 \mathrm{~min}$ and allowed to solidify in a slanted position on racks.

For surface sterilization, achenes were wrapped in cheese cloth, placed into a $0.5 \%(\mathrm{v} / \mathrm{v})$ sodium hypochlorite (Lilo Products, Hamilton, Ont.) solution containing Tween $20\left(2.0 \mu \mathrm{L} \cdot \mathrm{L}^{-1}\right)$ and placed on an orbital shaker (Labline Instruments, Melrose Park, Ill.) for 20-30 min. Agitation continued through three transfers into vials of sterile deionized water to remove the sodium hypochlorite solution. Achenes were placed on moistened sterilized filter paper to prevent desiccation, and the distal third of each achene was removed with a scalpel and discarded. Cutting occurred under a dissecting microscope (Aus JENA, Jena, Germany) in a laminar flow hood (Canadian Cabinets Co., Ottawa, Ont.). Cut achenes were replaced in vials on the surface of the medium described above. These vials were placed on racks and in a tissue culture growth room maintained at $20^{\circ} \mathrm{C}, 30 \mathrm{~cm}$ below $40-\mathrm{W}$ cool-white flourescent lights (Sylvania, Mississauga, Ont.) at $70 \mu \mathrm{mol} \cdot \mathrm{m}^{-2} \cdot \mathrm{s}^{-1}$ (photosynthetically active radiation). Seeds usually germinated and had fully expanded cotyledons within $10 \mathrm{~d}$ of being cut and placed on the media.

Data ANALYsis. The following traits were measured, fruit number, average number of seeds per fruit, seeds with embryos (precent) and germination (percent). Data were analyzed with the GLM program of SAS (SAS for Windows version 6.12; SAS
Inst., Cary, N.C.). Comparison of means was accomplished using the LS means function. Analysis of fruit number and seeds per fruit was based on the total number of accessions in a species combination, while seeds with embryos (percent) and germination (percent) were based on a subset of those combinations that received in vitro germination.

\section{Results}

The control crosses with $F$. vesca (vw69) verified that both emasculation and pollen storage techniques were successful (data not reported). The number of potential combinations of parents was limited by flowering times of different accessions within a species. There were 191 unique parental combinations achieved by 360 interspecific hybridizations. The four $F$. vesca subspecies were successfully hybridized with the four species used as the pollen parent. The species, nil1, nub1, nub2, pen1, vir1, and vir2 were used in $37,38,28,27,35$, and 36 hybrid combinations, respectively. Pen 1 produced trusses with only one to three flowers and was used in fewer combinations. Plants of ssp. bracteata had fewer flowers per plant than other $F$. vesca subspecies in the study so fewer crosses occurred with this group. Since data on the individual accessions were nonsignificant only means of the subspecies are presented. However among the many accessions used in this study, some had higher crossability indicators.

Fruit NUMBER AND SEEDS PER FRUIT. Pollen donor species were a significant source of variation for fruit number and average seed number but $F$. vesca subspecies and the interaction sources of variation were not significant. The $F$. nilgerrensis accession, nill, had the lowest fruit number, $39 \%$, while other pollen donors averaged between $80 \%$ and $100 \%$ (Table 3). Crosses having the nill accession as a male also had the lowest total seed number (33). Species used as pollen donors (i.e., nub2, pen1, vir1, and vir2) produced seeds per fruit averaging from 15 to 20 , while nub1 was highest with 25 seeds per fruit (Table 3).

The European subspecies vesca var. semperflorens produced the highest average fruit number (18) and was significantly higher than ssp. bracteata, a North American subspecies (Table 3).

SEEDS WITH EMBRYos AND EMBRYo GERMINATION. Insufficient numbers of hybrid seeds were produced with $F$. vesca ssp. bracteata females to allow meaningful analysis of variance (ANOVA) of differences among $F$. vesca subspecies for the proportion of seeds with embryos and percent embryo germination. Therefore, only the effect of male accessions was incorporated into ANOVAs of these two variables (data not reported). Male accessions were significantly different for percent of seeds with embryos but not for in vitro embryo germination (Table 4). The percentage of seeds with embryos was greater than $75 \%$ for all accessions. Four species used as pollen donors were at least 13\% higher then nil1 or vir2 for percentage of seeds with embryos (Table 4). Percent embryo germination (in vitro) was similar for all males, with only a $12 \%$ difference between the lowest (vir2) and highest (vir1) male.

After germination, all seedlings were allowed to reach maturity to confirm longer term viability and fertility. These hybrids were subsequently used in advanced phases of the synthetic octoploid system.

\section{Discussion}

This study used a far greater number (39) of $F$. vesca accessions than those used in other studies of interspecific hybridization of 
Table 3. Number of crosses (N), fruit number and total number of seeds for crosses among Fragaria vesca subspecies when pollinated with $F$. nilgerrensis (nil 1), F. nubicola (nub 1 and 2), F. pentaphylla (pen 1), and F. viridis (vir1 and 2).

\begin{tabular}{|c|c|c|c|c|c|c|c|c|c|c|c|c|c|c|c|c|c|c|c|c|c|}
\hline \multirow{5}{*}{$\begin{array}{l}\text { F. vesca } \\
\text { subspecies } \\
\text { used as } \\
\text { females }\end{array}$} & \multicolumn{18}{|c|}{ Species accessions used as pollen donors } & & & \\
\hline & \multirow{2}{*}{\multicolumn{3}{|c|}{$\begin{array}{l}\text { F. nilgerrensis } \\
\text { (nil1) }\end{array}$}} & \multicolumn{6}{|c|}{ F. nubicola } & \multirow{2}{*}{\multicolumn{3}{|c|}{$\begin{array}{c}\text { F. pentaphylla } \\
\text { (pen1) }\end{array}$}} & \multicolumn{6}{|c|}{ F. viridis } & \multirow{2}{*}{\multicolumn{3}{|c|}{ Mean $^{2}$}} \\
\hline & & & & & (nub1 & & & (nub2) & & & & & & (vir1) & & & (vir2 & & & & \\
\hline & & & Seeds & & & Seeds & & & Seeds & & & Seeds & & & Seeds & & & Seeds & & & \\
\hline & $\mathrm{N}$ & $\begin{array}{l}\text { Fruit } \\
\text { (no.) }\end{array}$ & $\begin{array}{l}\text { (no./ } \\
\text { fruit }\end{array}$ & $\mathrm{N}$ & $\begin{array}{l}\text { Fruit } \\
\text { (no.) }\end{array}$ & $\begin{array}{l}\text { (no./ } \\
\text { fruit) }\end{array}$ & $\mathrm{N}$ & $\begin{array}{l}\text { Fruit } \\
\text { (no.) }\end{array}$ & $\begin{array}{l}\text { (no./ } \\
\text { fruit) }\end{array}$ & $\mathrm{N}$ & $\begin{array}{l}\text { Fruit } \\
\text { (no.) }\end{array}$ & $\begin{array}{l}\text { (no./ } \\
\text { fruit) }\end{array}$ & $\mathrm{N}$ & $\begin{array}{l}\text { Fruit } \\
\text { (no.) }\end{array}$ & $\begin{array}{l}\text { (no./ } \\
\text { fruit) }\end{array}$ & $\mathrm{N}$ & $\begin{array}{l}\text { Fruit } \\
\text { (no.) }\end{array}$ & $\begin{array}{l}\text { (no./ } \\
\text { fruit) }\end{array}$ & $\begin{array}{c}\text { Total } \\
\mathrm{N}\end{array}$ & $\begin{array}{l}\text { Fruit } \\
\text { (no.) }\end{array}$ & $\begin{array}{c}\text { Seeds } \\
\text { (no.) }\end{array}$ \\
\hline americana & 26 & 7 & 4 & 8 & 8 & 27 & 10 & 8 & 14 & 7 & 7 & 17 & 31 & 22 & 19 & 14 & 12 & 20 & 96 & $11 \mathrm{ab}$ & $17 \mathrm{a}$ \\
\hline vesca & 26 & 11 & 1 & 11 & 11 & 24 & 11 & 11 & 19 & 12 & 11 & 15 & 11 & 10 & 11 & 12 & 10 & 14 & 82 & $11 \mathrm{ab}$ & $14 \mathrm{a}$ \\
\hline $\begin{array}{l}\text { vesca var. } \\
\text { semperflorens }\end{array}$ & 45 & 23 & 4 & 10 & 10 & 22 & 12 & 9 & 18 & 8 & 8 & 17 & 27 & 26 & 13 & 34 & 33 & 6 & 136 & $18 a$ & $13 a$ \\
\hline bracteata & 14 & 3 & 4 & 5 & 5 & 26 & 7 & 3 & 28 & 6 & 5 & 24 & 6 & 5 & 13 & 8 & 7 & 18 & 46 & $5 \mathrm{~b}$ & $19 a$ \\
\hline $\operatorname{Mean}^{y}$ & 28 & $11 a$ & $3 c$ & 9 & $9 a$ & $25 a$ & 10 & $8 a$ & $20 a b$ & 8 & $8 a$ & $18 \mathrm{~b}$ & 19 & $16 a$ & $14 \mathrm{~b}$ & 17 & $16 a$ & $15 b$ & & & \\
\hline
\end{tabular}

${ }_{\mathrm{z}}$ Means within a column followed by the same letter are not significantly different at $P=0.05$.

y Means of the same trait within a row followed by the same letter are not significantly different at $P=0.05$.

Table 4. Seeds with embryos (percent) and embryo germination (percent) for interspecific crosses among Fragaria vesca accessions used as female parents with four diploid species as pollen donors.

\begin{tabular}{lccccc}
\hline $\begin{array}{l}\text { Fragaria } \\
\text { species used as } \\
\text { pollen donors }\end{array}$ & $\begin{array}{c}\text { Accession } \\
\text { code }\end{array}$ & $\begin{array}{c}\text { Female F. vesca } \\
\text { accessions used in } \\
\text { crosses (no.) }\end{array}$ & $\begin{array}{c}\text { Total seeds } \\
\text { germinated in } \\
\text { vitro (no.) }\end{array}$ & $\begin{array}{c}\text { Seeds } \\
\text { with viable } \\
\text { embryos (\%) }\end{array}$ & $\begin{array}{c}\text { In vitro embryo } \\
\text { germination (\%) }\end{array}$ \\
\hline F. nilgerrensis & nil1 & 15 & 108 & $75 b^{2}$ & $85 a$ \\
F. nubicola & nub1 & 12 & 324 & $97 a$ & $81 a$ \\
F. pentaphylla & nub2 & 17 & 397 & $99 a$ & $84 a$ \\
F. viridis & ven1 & 21 & 490 & $92 a$ & $81 a$ \\
& vir1 & 11 & 241 & $99 a$ & $89 a$ \\
\hline \multicolumn{1}{c}{ Mean } & 6 & 14 & 308 & $79 a b$ & $77 a$ \\
\hline
\end{tabular}

${ }^{\mathrm{z}}$ Means followed by the same letter are not significantly different at $P=0.05$ level.

diploid Fragaria. The current study thus provides a better representation of the diversity within $F$. vesca compared to earlier studies. F. vesca subspecies did not differ statistically in interspecific crossability in this study although considerable variation for crossability was present among the accessions within a subspecies (data not reported). The interactions among $F$. vesca subspecies and four other species were not statistically different for any of the variables investigated. The hypothesis that $F$. vesca subspecies differ in interspecific crossability (Fadeeva, 1966; Williams, 1959) was not supported statistically by the results when averaged over a large number of accessions. Since the genotypes within each of the $F$. vesca subspecies ranged widely in crossability, it is quite possible that smaller collections of $F$. vesca subspecies commonly used in previous studies could skew results leading to the erroneous conclusion that some subspecies were superior. For example, in a past study (Fadeeva, 1966) the conclusion that cultivars of $F$. vesca var. semperflorens were superior over wild types for interspecific crossability was based on only two accessions of $F$. vesca var. semperflorens and an undisclosed number of wild accessions of $F$. vesca.

The ability of $F$. vesca to hybridize with four other diploid species validates the hypothesis that $F$. vesca could be a very useful bridge species for the first steps of the synthetic octoploid system. Fragaria breeders wishing to use $F$. vesca as a bridge species could use any of these subspecies of $F$. vesca with a high likelihood of success. Since most $F$. vesca accessions hybridized with most other species in the experiment with the exception of $F$. nilgerrensis, it may be advantageous to focus on $F$. vesca accessions with superior horticultural qualities when introgressing other species. Qualities such as larger fruit size or disease resistance may make an accession more desirable to use, even if only a few seeds were produced in interspecific hybridization. Fadeeva (1966) observed a positive correlation between fruit size of $F$. vesca parental lines and fruit size of interspecific hybrids. Using a well-adapted subspecies would also be an appropriate strategy. If prebreeding were to occur at the diploid level as part of the synthetic octoploid system, this study suggests some variation exists among the accessions and choosing appropriate accessions within subspecies could lead to higher performance levels in the hybrids.

Fragaria vesca has been proposed as a progenitor species within Fragaria (Duchesne in Darrow, 1966; Nurnberg-Kruger, 1958; Staudt, 1953). The current study would support this theory due to the crossability between $F$. vesca and the other diploid species tested. Potter et al. (2000) determined that $F$. vesca and $F$. nubicola were the species most closely related to the tetraploid, hexaploid and octoploid Fragaria species. F. iinumae from China and Japan is believed to be the most ancestral species previously examined (Harrison et al., 1997; Potter et al., 2000). The lack of divergence among the $F$. vesca subspecies in the current study 
would suggest it is a younger species (Potter et al., 2000) but it could have been involved in the formation of polyploid species (Bringhurst, 1990; Bringhurst and Senanayake, 1967; Federova, 1946; Staudt, 1959).

The $F$. vesca subspecies demonstrated similar levels of crossability even though they were found in diverse regions. Phylogenetic analysis confirmed the $F$. vesca subspecies (from California, Finland, Nebraska, Sweden, and Washington) were indeed closely related (Potter et al., 2000). Fragaria vesca's adaptation to low light levels enabling it to survive in forest ecosystems (Chabot and Chabot, 1977) may be responsible for its wide distribution throughout the northern continents (Reed, 1966; Staudt, 1989) despite being a young species. Fragaria vesca could have migrated during the Miocene (23-5.3 million years ago) with numerous forest species across intercontinental land bridges connecting Asia, North America and Europe (Constance, 1972; Hara, 1972; Li, 1972; Stebbins, 1950). The octoploids $F$. virginiana and chiloensis are believed to have arrived in North America via this route (Harrison et al., 1997; Potter et al., 2000). This would explain the morphological similarities between ssp. vesca of Europe and ssp. americana of eastern North America (Staudt, 1989) and the similar levels of crossability observed in this study. Only those Fragaria species adapted to northern latitudes and forest ecosystems could have migrated to North America via northern land bridges.

The crossability results of this study and phylogenetic analysis (Potter et al., 2000) confirm that $F$. pentaphylla, $F$. nubicola, and $F$. viridis are closely related to $F$. vesca. The $F$. vesca $\times F$. pentaphylla hybrids have not been previously reported. It was surprising the $F$. pentaphylla had similar crossing results to that of $F$. viridis and $F$. nubicola as this species has unique leaf and fruit morphology suggesting at least some divergence.

The results obtained in this study concur with other research (Evans, 1964; Williams, 1959) which showed that $F$. vesca $\times F$. nilgerrensis hybrids are difficult to obtain. To explain these findings, $F$. nilgerrensis is classed as divergent from other diploid species (Harrison et al., 1993, 1997). Earlier studies identified only three $F$. vesca accessions with potential to produce healthy hybrids with $F$. nilgerrensis (Evans, 1964; Williams, 1959; Yarnell, 1931). In this study, 19 F. vesca accessions were found that produced hybrid seeds. Seedling stunting (Fadeeva, 1966; Yarnell, 1931) and lethal seedlings (Williams, 1959) have been previously observed in $F$. vesca $\times F$. nilgerrensis hybrids. The lack of these phenomena in this study indicates variability in $F$. nilgerrensis and perhaps specific accessions, such as nil1, are superior for interspecific hybridization with $F$. vesca. While it has been suggested that $F$. nilgerrensis cannot be introgressed into the genepool of cultivated strawberries (Hancock et al., 1996), the current study shows encouraging progress toward this goal.

Other differences existed between this and earlier studies. The results of $F$. vesca $\times F$. nilgerrensis crosses were particularly noteworthy in this study since very few successful crosses between these two species had been reported previously. If percent seed with embryo is multiplied with percent embryo germination (Table 4), the number of germinating seeds is higher than previous results. For the $F$. vesca $\times F$. viridis, $F$. vesca $\times F$. nubicola, and $F$. vesca $\times F$. nilgerrensis combinations in this study, germination rates were $13 \%, 5 \%$, and $0 \%$ higher, respectively, than earlier studies. While the use of in vitro germination did not dramatically increase germination rates compared to traditional methods, it provided additional information regarding the germination of interspecific hybrids. For the combinations of species with low success rates significant differences among the various combinations of species (Table 4) were due to embryo abortion during seed formation (i.e., seeds with embryos) and not germination rates of fully formed embryos (i.e., embryo germination).

This study was successful in producing many hybrids between $F$. vesca and other diploid species, including the difficult to obtain $F$. vesca $\times F$. nilgerrensis hybrids. The lack of significant differences in crossability variables among the four types of $F$. vesca demonstrated that the $F$. vesca subspecies were all acceptable for interspecific hybridization with any of the other four diploid species used in this study and confirms that these species are closely related. Crossability of $F$. vesca indicates that strong potential exists for geneflow between $F$. vesca and other diploid species. Although the number of accessions of other diploid Fragaria species was limited, F. vesca hybridized with the four other diploid species used in this study, indicating good potential as a bridge species in the synthetic octoploid system. Limitations of germplasm make it impossible to conclude that $F$. vesca is the best bridge species available, and another study (Potter et al., 2000) has shown that $F$. nubicola, like $F$. vesca, is closely related to the octoploid Fragaria. As European and North American $F$. vesca subspecies are not divergent enough to differ in interspecific hybridization, it seems more likely that $F$. vesca is a younger rather than a progenitor species. An explanation for the global distribution of $F$. vesca is that specialized physiological adaptations have allowed $F$. vesca to spread in forest ecosystems. This theory provides an alternative to previous theories of $F$. vesca evolution (Duchesne in Darrow, 1966; Longley in Darrow, 1966; Nurnberg-Kruger, 1958; Staudt, 1953).

\section{Literature Cited}

Ahmadi, H. and R.S. Bringhurst. 1990. Modes of inheritance of photoperiodism in Fragaria. J. Amer. Soc. Hort. Sci. 115:146-152.

Ahmadi, H. and R.S. Bringhurst. 1991. Genetics of sex expression in Fragaria species. Amer. J. Bot. 78(4):504-514.

Ahmadi, H. and R.S. Bringhurst. 1992. Breeding strawberries at the decaploid level. J. Amer. Soc. Hort. Sci. 117:856-862.

Bauer, R. 1976. New patterns of heterosis in Fragaria hybrids, p. 63-68. In: A. Janossy and F.G.H. Lupton (eds.). Heterosis in plant breeding. Proc. 7th Congr. Eucarpia. Elsevier, New York.

Bringhurst, R.S. 1990. Cytogenetics and evolution in Fragaria. HortScience 25:879-881.

Bringhurst, R.S. and Y.D.A. Senanayake. 1966. The evolutionary significance of natural Fragaria chiloensis $\times F$. vesca hybrids resulting from unreduced gametes. Amer. J. Bot. 53:1000-1006.

Bringhurst, R.S. and T. Gill. 1970. Origin of Fragaria polyploids. II. Unreduced and double reduced gametes. Amer. J. Bot. 57(8):969-976.

Chabot, B.F. and J.F. Chabot. 1977. Effects of light and temperature on leaf anatomy and photosynthesis in Fragaria vesca. Oecologia 26:363-377.

Constance, L. 1972. Patterns in the distribution of Japanese-American Umbelliferae, p. 93-99. In: G. Graham (ed.). Floristics and paleofloristics of Asia and Eastern North America. Elsevier, New York.

Darrow, G.M. 1966. The strawberry. Holt, Rinehart, and Winston, New York.

Evans, W.D. 1964. Cytogenetic investigations in the genus Fragaria. $\mathrm{PhD}$ thesis. Univ. of Reading, England.

Evans, W.D. 1974. Evidence of a crossability barrier in diploid x hexaploid and diploid $\times$ octoploid crosses in the genus Fragaria. Euphytica 23:95-100.

Evans, W.D. 1977. The use of synthetic octoploids in strawberry breeding. Euphytica 26:497-503.

Evans, W.D. and J.K. Jones. 1967. Incompatibility in Fragaria. Can. J. Genet. Cytol. 9:831-836. 
Fadeeva, T.S. 1966. Problems of comparative plant genetics: Communication 1. Principles of genome analysis (with reference to the genus Fragaria). Genetika 2:6-16.

Federova, N.J. 1946. Crossability and phylogenetic relations in the main European species of Fragaria. Compt. Rend. (Doklady) Acad. Sci. USSR. 52:545-547.

Gustafson, J.P. and A.R. Dera. 1989. Alien gene manipulation and expression in wheat. Genome 31:134-136.

Gustafson, J.P. and E.R. Sears. 1993. An effective wheat gene manipulation system: Problems and uses. Plant Breeding Rev. 11:225-234.

Hancock, J.F., D.H. Scott, and F.J. Lawrence. 1996. Strawberries, p. 419-470. In: J. Janick and J.N. Moore (eds.). Fruit breeding, vol. 2. Wiley, New York.

Hara, H. 1972. Corresponding taxa in North America, Japan and the Himalayas, p. 61-72. In: D.H. Valentine (ed.). Taxonomy, phytogeography and evolution. Academic, New York.

Harrison, R.E., J.J.Luby, and G.R. Furnier. 1993. Molecular investigation of the chloroplast genome in Fragaria spp. Acta Hort. 348:395-402.

Harrison, R.E., J.J. Luby, and G.R. Furnier. 1997. Chloroplast DNA restriction fragment variation among strawberry (Fragaria spp.) taxa. J. Amer. Soc. Hort. Sci. 122:63-68.

Li, H.L. 1972. Eastern Asia-eastern North American species-pairs in wide ranging genera, p. 65-78. In: G. Graham (ed.). Floristics and paleofloristics of Asia and Eastern North America. Elsevier, New York.

MacFarlane Smith, W.H., J.K. Jones, and A.R. Sebastiampillai. 1989. Pollen storage of Fragaria and Potentilla. Euphytica 41:65-69.

Miller, A.R., J.C. Scheerens, and P.S. Erb. 1992. Enhanced strawberry seed germination in vitro of cut achenes. J. Amer. Soc. Hort. Sci. 117:313-316.

Nurnberg-Kruger, U. 1958. Genetical investigation on diploid Fragaria species. I. The cross between $F$. vesca and $F$. nilgerrensis, its effect on the morphology of the plants and the development of sex. Zeitschrift Vererbungslehre 89:747-773.

Potter, D., J.J. Luby, and R.E. Harrison. 2000. Phylogenetic relationships among species of Fragaria (Rosaceae) inferred from non-coding nuclear and chloroplast DNA sequences. Systematic Bot. 25(2):337-348.

Reed, C.F. 1966. The strawberry species, p. 108-129. In: G.M. Darrow (ed.). The strawberry. Holt, Rinehart, and Winston, New York.

Sebastiampillai, A.R. and J.K. Jones. 1976. Improved techniques for the induction and isolation of polyploids in the genus Fragaria. Euphytica 25:725-732.

Senanayake, Y.D.A. and R.S. Bringhurst. 1967. Origin of Fragaria polyploids. I. Cytological analysis. Amer. J. Bot. 54(2):221-228.

Staudt, G. 1953. Zur selbsterilitat von Fragaria viridis Ouch. Naturwissenschaften 24:572-574.

Staudt, G. 1959. Cytotaxonomy and phylogenetic relationships in the genus Fragaria. Proc. Ninth Intl. Bot. Congr. 2:377.

Staudt, G. 1967. Die genetik und evolution der heterozie in der gattung Fragaria, I. Untersuchungen an Fragaria orientalis. Z. Pflanzenzuchtung 58:245-277.

Staudt, G. 1989. The species of Fragaria, Their taxonomy and geographical location. Acta Hort. 265:23-33.

Stebbins, G.L., Jr. 1950. Variation and evolution in plants. Columbia Univ. Press, New York.

Stoskopf, N.C., D.T. Tomes, and B.R. Christie. 1993. Plant breeding theory and practice. Westview Press, Boulder, Colo.

Trajkovski, K. 1993. Progress report on Fragaria species hybridization at Balsgard, Sweden. Acta Hort. 348:131-136.

Williams, W. 1959. Department of Plant Breeding: Mr. Williams's report. John Innes Hort. Inst., 15th Annu. Rpt. p. 7-16.

Yarnell, S.H. 1931. Genetic and cytological studies on Fragaria. Genetics 16:422-454. 